\title{
Occupational Therapy in Cancer Survivorship-A Toolkit for Stimulating Rapid-Research on the Neglected Domain of "Participation" during COVID-19
}

\author{
Siew Yim Loh \\ Faculty of Medicine, University of Malaya, Kuala Lumpur, Malaysia \\ Email: syloh@um.edu.my
}

How to cite this paper: Loh, S.Y. (2021) Occupational Therapy in Cancer Survivorship-A Toolkit for Stimulating RapidResearch on the Neglected Domain of "Participation" during COVID-19. Health, 13, 637-646.

https://doi.org/10.4236/health.2021.136048

Received: May 4, 2021

Accepted: June 6, 2021

Published: June 9, 2021

Copyright (อ 2021 by author(s) and Scientific Research Publishing Inc. This work is licensed under the Creative Commons Attribution International License (CC BY 4.0).

http://creativecommons.org/licenses/by/4.0/

(c) (i) Open Access

\begin{abstract}
COVID-19 has disrupted people's occupational daily activities with detrimental impact on their daily living performances and quality of life. Occupational therapy contributes toward restoring health by remediating limitation in participation in meaningful occupation with lifestyle redesign interventions. However, the research gap on the area of "participation-limitation" for the field of Occupational Therapy in cancer survivorship during the COVID-19 is largely untapped and unknown. This commentary-review paper discussed the PEOOT (person-environment-occupation) grid as a conceptual toolkit for stimulating research in the domain of occupational participation-an essential aspect in the field of occupational therapy, for cancer survivors. It applies the expertise finding from a large Delphi study on research priority in the fields and integrating these into evidenced methodology, to provide a structure to guide the novice researchers towards rapid reviews, by selecting evidencebased methods to ensure contextually-relevant enquiry to identify the "occupational-participation issues"-i.e., an emerging social determinant of health, affecting the daily self-management of cancer survivors with or without comorbidities.
\end{abstract}

\section{Keywords}

Cancer Survivor, COVID-19 Environment, Rapid Response Research, Research Development, Research Toolkit, Occupational Therapy, PEO.OT Grid

\section{Background}

In 2021, Global cancer statistics 2020 estimated 19.3 million new cancer cases 
(up to February 2021) for 36 cancers in 185 countries. There are 43.8 million cancer survivors diagnosed in the last 5 years; and half of this number is occurring in Asia [1]. The COVID-19 pandemic is overwhelming health systems in many countries, where non-COVID-19 cases are greatly reduced to either make way for COVID-19 infested cases, or to minimise the risk-exposure. WHO-China [2] alert that, 14 percent of COVID-19 patients had respiratory distress syndrome, and 6 percent had respiratory failure. Patients with one comorbidity (e.g., cardiovascular, diabetes, hepatitis B, chronic pulmonary disease, chronic kidney diseases, and cancer) had almost 80 percent higher need for intensive care, and the risk is 2.5 times more for those with more than one comorbidity [3]. Although China has 4.3 million (24 percent of world total) of new cancer cases [1], yet there are relatively few reports on impact among cancer survivors. The risk of getting ill from COVID-19 infection is higher in cancer patients due to their immunocompromised status from prolonged treatment [4] and also from restricted follow-up due to the environmental barriers. Malaysia was amongst the countries that enforced strict movement control during COVID-19, with a complete lockdown restricting travel and commerce [5] [6], resulting in normal life being suspended for indefinite periods, causing much uncertainties-related emotions, finance and occupational distress. The International Labour Organisation have cautioned that 40 percent of the world's population have no health insurance nor are able to access national health services resulting in debilitating consequences-where 100 million people fall into poverty due to health expenses [7].

Participation restrictions and the uncertainties associated with COVID-19, and its impacts on the physical-mental-social wellbeing of cancer survivors are still unknown. Across Asia, there are issues of low workforce, and issues of limited research output in the field of occupational therapy [8]. Occupational Therapy is an evidence-based science discipline focusing on remediating dysfunctions to enable patients across all ages and medical conditions, to regain their functional independence in daily-living participations [9] [10] [11] [12]. Evidence from occupational therapy's lifestyle intervention in community-dwelling elders is promising, and a growing demand for occupational therapists to help facilitate functional participation of patients [13] has been document in USA. There is a dire need to employ occupational therapists in primary care clinics to address participation issues from demands for new norms, habits and lifestyle adjustments, and the associated mental health issues during the pandemic [14] [15] [16] [17] [18]. Rapid response evidences can inform timely interventions for the afflicted cancer survivors. Rapid reviews are an efficient solution to support policy makers and health providers to collate timely, relevant and contextualised evidences [19] [20]. Rapid review through proper systematic reviews or scoping knowledge synthesis is recognised as scientifically sound means to gather and analyze timely evidence for health [21] [22]. Tailored rapid review reports on cancer survivors during COVID-19 may have numerous barriers for implementation [23] [24], especially in the contextual person-environmental-occupation factors, essential in the field of occupational therapy. 
COVID-19 has created a big chasm of unknowns including research needs, with much uncertainties. Liang and collegues [25] gave a preliminary conclusion that cancer survivors ( $\mathrm{n}=18$ out of 1590 Covid-19 cases) have higher risk of COVID19 and with poorer prognosis. Zhou and collegues [26] attempt to highlight priority treatment for cancer patients during the pandemic. Two missing research aspects that needs greater work evidence in occupational therapy with cancer survivors are participation limitation and patient self-management [27] [28].

Occupational therapists need the research evidence to enable cancer survivors to engage in daily participation, and be effective in self-managing their daily occupational participation, through daily monitoring of their condition and make whatever cognitive, behavioural, and emotional changes needed to maintain a satisfactory quality of life. Patient self-management is the patient's ability to deal with everything that having a chronic condition, entails and it includes, managing the symptoms, treatment, emotional impact, physical and social consequences, and lifestyle changes, and there is evidence of effectiveness in woman with breast cancer [28]. Occupational participation is a key significant outcome in occupational therapy rehabilitation [27] [28] [29], and has been measured in breast and colorectal cancer survivors using the occupational participation questionnaire [12] [26]. Within these concepts, the Person-Environment-Occupation (PEO) model [30] described occupational performance (or occupational participation) as shaped by the interplay between 1) Person (i.e. role, self-concept, cultural background, personality, health, cognition, physical performance, and sensory capabilities), 2) environment (physical, cultural, institutional, social, and socioeconomic environment), and 3) occupation (i.e. groups of tasks individual participated in to meets self-maintenance, expression and fulfilment). As a model, $\mathrm{PEO}$ can be used as an assessment tool, in practice and in research, to understand and analyse problematic areas that affect clients' occupational performance [30] [31] [32].

Therefore, the neglected area participation-limitations are key domains in Occupational therapy, requiring more research to be stimulated and explore. However, rapid, timely research to inform interventions that supports the rising cancer survivors to better self-manage living with cancer effectively, are scare and efforts are complicated by low manpower rendering it as an area relatively untapped during the COVID-19 pandemic. Thus, this paper aims to stimulate a rapid-response for research priority in the neglected domain of participation issues, in Occupational therapy for cancer survivors during the COVID-19 pandemic.

\section{Methodology}

This review draws from the years of expertise' experience within the field of the cancer survivorship and occupational therapy (which are both relatively new in the healthcare of many developing countries). Using a flow process involving 3 -sequential steps, rapid-review proceeding (Figure 1), novice researchers are guided to the overall process of planning, structuring and refining questions for research in the area. 


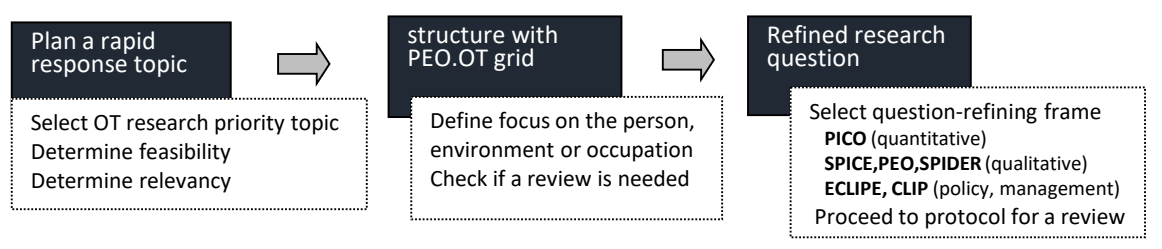

Figure 1. Flow chart for rapid-response research on participation.

Two key occupational therapy documents were used for this paper: the Person-Environment-Occupation (PEO) Model [32] [33], and the recent findings from the World Federation of Occupational Therapists' (WFOT) on research priorities [34].

The three horizontal themes from the PEO model were utilised in the second step of conceptualising this research process for a conceptual toolkit to facilitate research in the area. The three themes of 1) Person-related, 2) Environment related and 3) Occupation-related context for therapy were used as the vertical theme in the grid, to generate a PEO.OT Grid. Using this Person-Environment-Occupation (PEO) model, it helps identify the occupational performance, shaped by the interaction between person, environment, and occupation [31] [32] [33].

Next, the second document (i.e. the WFOT document) with key significant research findings (derived from rigorous Delphi techniques with member organisations) on Occupational therapy research priority areas was used. Seven of the eight key priority areas were selected for inclusion into the PEO.OT Grid (Table 1). The Occupational therapy professional issue was not selected as its too specific into profession-development issue. The remaining seven themes or Occupational therapy areas were: 1) Participation in everyday life 2) Occupational therapy and Non communicable diseases/Cancer 3) Effectiveness of interventions, 4) Evidence-based practice \& Knowledge translation, 5) Healthy Aging, 6) Community development and populations, and 7) Technology and occupational therapy.

\section{Results}

The result of these cognitive deliberations using findings from research and established research methods, resulted in a PEO.OT Grid toolkit (Table 1) which served as a potential decision-aid tool to frame broad research questions, but focussed on issues related to Occupation therapy in cancer survivorship.

\section{Question-Refinement Guides-for Qualitative, Quantitative and Policy Research}

The novice and limited novice researchers can build up the broad questions using the evidence-based tool such as PICO (for quantitative clinical research topics) SPICE, PEO or SPIDER (for qualitative research topics), ECLIPSE or CLIP (for health management, policies). Table 2 present six guide for refining a good research question according to whether it is 1) qualitative, 2) quantitative or 3) policy research [34] [35] [36] [37] [38]. The Commission on Social Determi- 
nants of Health called for governments to redirect health focus on social determinants, due to the increasing evidence of social contributions to health inequities [39]. This perspective is a timely call for the relevant health workers such as occupational therapists, to engage in integrated, contextually relevant and affordable care deliveries. The measures of impacted areas of occupational participation from the occupational therapy's perspective on the use of environments and contexts to facilitate health and well-being is timely during this pandemic of COVID-19 [40].

Table 1. The PEO.OT grid (Person-environmental-occupation in Occupational therapy, Research-priority Grid).

\begin{tabular}{|c|c|c|c|}
\hline PRIORITY THEME & PERSON \& (Covid-19) & ENVIRONMENT \& (COVID-19) & OCCUPATION\& (COVID-19) \\
\hline $\begin{array}{l}\text { Participation in everyday } \\
\text { life (PIEL) }\end{array}$ & $\begin{array}{l}\text { Socio-demographic predictors of } \\
\text { PIEL, and impact on QOL }\end{array}$ & $\begin{array}{l}\text { Extent of PIEL adjustment during } \\
\text { lockdown, and explore feelings. }\end{array}$ & $\begin{array}{l}\text { Changes in occupation participation } \\
\text { for workers with cancer }\end{array}$ \\
\hline $\begin{array}{l}\text { Occupational Therapy } \\
\& \text { cancer /Chronic } \\
\text { conditions }\end{array}$ & $\begin{array}{l}\text { Psychological responses of Cs with } \\
\text { more co-morbidities, vs those with } \\
\text { less, Meaning of life } \\
\text { (Impact of comorbidities on QOL of } \\
\text { CS during COVID-19) }\end{array}$ & $\begin{array}{l}\text { Capacity building on Occupational } \\
\text { Therapy workforce in Primary health } \\
\text { care for cancer survivors during } \\
\text { Covid-19 }\end{array}$ & $\begin{array}{l}\text { Perception of safety at work with } \\
\text { Covid-19: comparison of cs with } \\
\text { /without comorbidities }\end{array}$ \\
\hline $\begin{array}{l}\text { Effectiveness of } \\
\text { interventions }\end{array}$ & $\begin{array}{l}\text { Supportive care to enable } \\
\text { "Engagement in meaningful activity": } \\
\text { older vs younger CS during shutdown }\end{array}$ & $\begin{array}{l}\text { Environmental redesign (I) for } \underline{\mathrm{CS}} \\
\text { with cognitive impairment }(\mathrm{P}) \text { to } \\
\text { maintain function }(\mathrm{O})\end{array}$ & $\begin{array}{l}\text { CBT to prepare Cancer survivor with } \\
\text { fear to return to work }\end{array}$ \\
\hline $\begin{array}{l}\text { Evidence-based practice \& } \\
\text { Knowledge translation }\end{array}$ & $\begin{array}{l}\text { Evidence of OT intervention for CS } \\
\text { during lockdown-barriers and } \\
\text { facilitator, use of tele-technology }\end{array}$ & $\begin{array}{l}\text { Telephone-buddy to encourage } \\
\text { walking during home confinement to } \\
\text { improve steps of CS }\end{array}$ & $\begin{array}{l}\text { CS in various work e.g. government vs } \\
\text { private: fear of layoff }\end{array}$ \\
\hline Healthy Aging & $\begin{array}{l}\text { Experience of living during lockdown: } \\
\text { Barriers and facilitator experienced by } \\
\text { older cancer survivors }\end{array}$ & $\begin{array}{l}\text { What environment supports can } \\
\text { promote participation of older CS }\end{array}$ & $\begin{array}{l}\text { What occupational engagement } \\
\text { predicts QOL in older people with CS } \\
\text { during movement controlled }\end{array}$ \\
\hline $\begin{array}{l}\text { Community development } \\
\text { and populations }\end{array}$ & $\begin{array}{l}\text { What were the participation impacts } \\
\text { of lockdown on CS living alone }\end{array}$ & $\begin{array}{l}\text { What community support is needed } \\
\text { for CS confined to their different } \\
\text { environment (flat/condo/house/....) }\end{array}$ & $\begin{array}{l}\text { Community support to facilitate } \\
\text { continuation of active treatment }\end{array}$ \\
\hline $\begin{array}{l}\text { Technology and } \\
\text { occupational therapy }\end{array}$ & $\begin{array}{l}\text { What tech are useful to aid living in } \\
\text { isolation-lesson for future }\end{array}$ & $\begin{array}{l}\text { Supportive care via e-health relaxation } \\
\text { for a group of CS who developed } \\
\text { anxiety }\end{array}$ & $\begin{array}{l}\text { Community video conferencing to } \\
\text { address psychosocial impact from } \\
\text { working from home. }\end{array}$ \\
\hline
\end{tabular}

CS: Cancer survivors; OT: Occupational Therapy; CBT Cognitive behavioural therapy [PEO.OT grid @Loh, 2021].

Table 2. Research questions frame (according to quantitative, qualitative or policy/economic).

\begin{tabular}{ll}
\hline FRAMING/structuring Research question & RESEARCH QUESTION \\
\hline PICO (QUANTITATIVE /CLINICAL STUDY) & $\begin{array}{l}\text { Example: Is an "OT lifestyle redesign" intervention, more } \\
\text { effective than drug-therapy for anxiety-management in }\end{array}$ \\
- Patient, Population or Problem - who and/or what is my question focused on? & $\begin{array}{l}\text { CS living alone during lock-down? } \\
\text { - Intervention-what intervention is being considered? }\end{array}$ \\
$\begin{array}{ll}\text { - Comparison-what intervention is being compared with (or not necessary) } \\
\text { - Outcomes-What do the research hope to achieve/improve/ affect? }\end{array}$ & $\begin{array}{l}\text { P-Adult cancer survivors (CS) } \\
\text { I-OT lifestyle redesign (alternative) to drugs? }\end{array}$ \\
& C-Drugs \\
& O-Reduction in stress
\end{tabular}




\section{Continued}

\section{SPICE (for QUALITATIVE)}

- Setting - where is the study set e.g., in a specific country, community, in a hospital, in a care home etc.

- Perspective-from whose perspective is the study done e.g., the patients, the health professionals., the carers etc.

- Intervention - what intervention is being examined?

- Comparison - is the intervention being compared with another?

- Evaluation-the outcome measures

\section{PEO (for QUALITATIVE )}

- Population-who is my question focussed on?

- Exposure-what is the issue I'm interested in?

- Outcomes or themes-what, in relation to the issue, do I want to examine?

\section{SPIDER (for QUALITATIVE TOPICS)}

- Sample-the group of people being looked at, because qualitative research is not to generalize, but to understand.

- Phenomenon of Interest-reasons for behaviour and decisions, rather than an intervention.

- Design - the form of research used, such as interview or survey

- Evaluation-outcome measures.

- Research type-qualitative, quantitative and/or mixed methods.
Example: What are the experiences of occupational therapy in older cancer survivor, and in what ways are they different from the experiences of younger cancer survivors, during the Covid-19? -implications for therapy delivery

S-(Kuala Lumpur/ Hospital)

$\mathrm{P}$-Cancer survivors -older vs younger

I-Hospital based rehabilitation/ therapy

$\mathrm{C}-\mathrm{NONE}$

E-Attitudes/experiences

Example: In what ways have distress intervention on mothers with breast cancer (during Covid 19 lockdown), improves their daily participation leading to better QOL

$\mathrm{P}-$ mothers with breast cancer

E-Stress, anxiety depression (DASS)

$\mathrm{O}-$ experiences of participation limitation

Example: In what ways have the experiences of attending hospital follow-up during covid-19, been distressing and what self-management strategies used have lower distress level?

S-Newly diagnosed breast cancer patients

PI-distress during lockdown

D-(focus group? interviews? surveys?)

E-Experiences

$\mathrm{R}$-(qualitative studies?)

\section{Discussion}

The PEO.OT grid (Table 1) as a conceptualised toolkit was formulated from this cognitive mapping process, with the aim to facilitate the novice therapists to structure their research question by focusing on the person-environment-occupation (PEO) constructs, within the intervention of occupational therapy (OT). This PEO-OT grid allows clinicians a directly focus into structuring for an area of cancer survivorship, to contributes to the needed data for expanding the occupational science knowledge-based. Once the research questions are formulated, refining using the established research methodology guide (see Table 2) to guide therapists towards an in-depth deliberation on the focussed topic from either a quantitative or qualitative approach. Table 2 will be useful to help redefine the specifics such as the population, setting, perspective, and evaluation to focus.

In general, this PEO.OT toolkit will help captures areas of occupational impacts or the ramifications of living with cancer during COVID-19, from an occupational perspective of an activity-based (occupation) living in the restricted pandemic environment, and to explore what are the associated outcomes associated with the physical, mental, social wellbeing of survivors. As the number of therapists are low in many developing countries, such toolkit can aid novice therapists/researchers in the field of cancer survivorship, to focus gathering the relevant evidence to inform their current intervention and future care from ano- 
ther pandemic. Using this PEO.OT grid, a guide on flow of research inquiry processes from planning, structuring to refining may help therapists to understand the experiences of cancer survivors living in the current pandemic.

\section{Conclusion}

In this era of prolonged COVID-19 pandemic, numerous impacts on health and also on daily-living participation are largely unknown. Participation limitation is an emerging social determinant of health, affecting the daily self-management of cancer survivors with or without comorbidities. This paper presents the application of the expertise finding from a large Delphi study (on research priority in the fields of Occupational therapy), into evidenced research methodology, to provide a conceptual-structure that guides the novice researchers towards rapid reviews, ensuring the results are contextually-relevant enquiries to identify the emerging "occupational-participation issue". A toolkit to facilitate novice researcher towards a rapid response to research can encourage the limited workforce and novice researchers in the field of occupational therapy to conduct the needed research, to inform practice, as well as for gathering evidence for policy and therapeutic care management. The PEO.OT grid is a potentially useful conceptualtoolkit to facilitate rapid decisions using evidence-based research methodology, to guide towards a contextually-relevant research topic on how the person (cancer survivors) and the COVID-19 environment, has impacted their daily living occupation (activities of daily living). These data are needed to inform occupational interventions to improve Quality of Life of cancer survivors. More research is needed on enabling patient self-management of the rising number of cancer survivors to improve effective living with cancer and its prolonged treatment but also, on aspects of recurrence prevention and health promotion.

\section{Conflicts of Interest}

The author declares no conflicts of interest regarding the publication of this paper.

\section{References}

[1] ACS (2020) The Burden of Cancer, The Cancer Atlas. https://canceratlas.cancer.org/the-burden/the-burden-of-cancer/

[2] WHO-China (2020) Report of the WHO-China Joint Mission on Coronavirus Disease 2019 (COVID-19).

https://www.who.int/docs/default-source/coronaviruse/who-china-joint-mission-o n-covid-19-final-report.pdf

[3] Begley, S. (2020) Who Is Getting Sick, and How Sick? A Breakdown of Coronavirus Risk by Demographic Factors. Health Stat News.

https://www.statnews.com/2020/03/03/who-is-getting-sick-and-how-sick-a-breakdo wn-of-coronavirus-risk-by-demographic-factors/

[4] Jacqueline, C., Tasiemski, A., Sorci, G., et al. (2017) Infections and Cancer: The "Fifty Shades of Immunity" Hypothesis. BMC Cancer, 17, Article No. 257. 
https://doi.org/10.1186/s12885-017-3234-4

[5] Fisher, D. and Wilder-Smith, A. (2020) The Global Community Needs to Swiftly Ramp up the Response to Contain COVID-19. The Lancet, 395, 1109-1110. https://doi.org/10.1016/S0140-6736(20)30679-6

[6] Diyana, P. (2020) Malaysia's Response to COVID-19 Ranked Fourth Strictest in SEA. The Star, Sunday, 12 April 2020.

https://www.thestar.com.my/news/nation/2020/04/12/malaysia039s-response-to-co vid-19-ranked-fourth-strictest-in-sea

[7] Razavi, S. (2020) International Labour Organization, COVID-19: Social Protection Systems Failing Vulnerable Groups, 25 March 2020.

www.ilo.org/global/about-the-ilo/newsroom/news/WCMS 739678/lang--en/index. htm

[8] Loh, S.Y., Khamis, K., Lee, P.C., Lee, M.H. and Ow, K.L. (2018) Research Activity, Skills and Training Needs of Health-Care Professionals-Call for Actions. JSM Health Education \& Primary Health Care, 3, 1045.

[9] Clark, F., Jackson, J., Carlson, M., et al. (2012) Effectiveness of a Lifestyle Intervention in Promoting the Well-Being of Independently Living Older People: Results of the Well Elderly 2 Randomised Controlled Trial. Journal of Epidemiology and Community Health, 66, 782-790. https://doi.org/10.1136/jech.2009.099754

[10] Bolt, M., Ikking, T., Baaijen, R. and Saenger, S. (2019) Occupational Therapy and Primary Care. Primary Health Care Research and Development, 20, e27. https://doi.org/10.1017/S1463423618000452

[11] Loh, SY. (2018) Occupational Participation Research-An Important Concept in Onco-Rehabilitation. JSM Physical Medicine and Rehabilitation, 2, 1009.

[12] Loh, SY. (2018) Self-Care or Self-Management in Palliative Survivorship Care in Asia: A Call for More Research. Nursing and Palliative Care, 3, 1-3. https://doi.org/10.15761/NPC.1000195

[13] Loh, S.Y., Sapihis, M., Danaee, M. and Chua, Y.P. (2020) The Role of Occupational Participation, Meaningful-Activity and Quality-of-Life of Colorectal Cancer Survivors: Findings from Path-Modeling. Disability and Rehabilitation. https://doi.org/10.1080/09638288.2020.1715492

[14] Meachum, A. (2020) Growing Demand for Occupational Therapists as Part of the Recovery Process for Coronavirus Patients. Nexstar Media Inc., Irving. https://www.arklatexhomepage.com/news/demand-for-occupational-therapists/

[15] (2016) World Federation of Occupational Therapists Human Resources Project 2016: Demographic Profile of WFOT Member Organisations. World Federation of Occupational Therapists Bulletin, 73, 76-79.

https://www.tandfonline.com/doi/abs/10.1080/14473828.2016.1275407

[16] Scheffler, R.M., Cometto, G., Tulenko, K., et al. (2016) Health Workforce Requirements for Universal Health Coverage and the Sustainable Development GoalsBackground Paper N.1 to the WHO Global Strategy on Human Resources for Health: Workforce 2030. World Health Organization, Geneva, Switzerland.

[17] Liu, J.X., Goryakin, Y., Maeda, A., Bruckner, T. and Scheffler, R. (2017) Global Health Workforce Labor Market Projections for 2030. Human Resources for Health, 15, Article No. 11. https://doi.org/10.1186/s12960-017-0187-2

[18] Loh, S.Y., Boniface, G., MacKenzie, L. and Richards, L. (2020) Occupational Therpay Profession for Women Health-Challenges for Its under Developed Services. Asian Journal of Occupational Therapy, 16, 35-43.

https://doi.org/10.11596/asiajot.16.35 
[19] Langlois, E.V., Straus, S.E., Antony, J., King, V.J. and Tricco, A.C. (2019) Using Rapid Reviews to Strengthen Health Policy and Systems and Progress towards Universal Health Coverage. BMJ Global Health, 4, e001178.

https://doi.org/10.1136/bmigh-2018-001178

[20] World Health Organization, Alliance for Health Policy and Systems Research (2021) Rapid Reviews to Strengthen Health Policy and Systems: A Practical Guide. https://www.who.int/alliance-hpsr/resources/publications/rapid-review-guide/en/

[21] Bosch-Capblanch, X., Lavis, J.N., Lewin, S., et al. (2012) Guidance for EvidenceInformed Policies about Health Systems: Rationale for and Challenges of Guidance Development. PLoS Medicine, 9, e1001185.

https://doi.org/10.1371/journal.pmed.1001185

[22] Oxman, A.D., Lavis, J.N., Lewin, S., et al. (2009) Support Tools for Evidence-Informed Health Policymaking (STP). Health Research Policy and Systems, 7, Article No. I1. https://doi.org/10.1186/1478-4505-7-S1-I1

[23] Tricco, A.C., Cardoso, R., Thomas, S.M., et al. (2015) Barriers and Facilitators to Uptake of Systematic Reviews by Policy Makers and Health Care Managers: A Scoping Review. Implement Science, 11, Article No. 4.

https://doi.org/10.1186/s13012-016-0370-1

[24] Tricco, A.C., Zarin, W., Ghassemi, M., et al. (2018) Same Family, Different Species: Methodological Conduct and Quality Varies according to Purpose for Five Types of Knowledge Synthesis. Journal of Clinical Epidemiology, 96, 133-142. https://doi.org/10.1016/j.jclinepi.2017.10.014

[25] Liang, W., Guan, W., Chen, R., et al. (2020) Cancer Patients in SARS-CoV-2 Infection: A Nationwide Analysis in China. The Lancet Oncology, 21, 335-337. https://doi.org/10.1016/S1470-2045(20)30096-6

[26] Zhou, F., Yu, T., Du, R., Fan, G., Liu, Y., et al. (2020) Clinical Course and Risk Factors for Mortality of Adult Inpatients with COVID-19 in Wuhan, China: A Retrospective Cohort Study. The Lancet, 395, 1054-1062. https://doi.org/10.1016/S0140-6736(20)30566-3

[27] Loh, S.Y. and Jonsson, H. (2016) Cancer Survivorship Care: A Perspective from an Occupational-Participation Approach, Journal of Cancer Science and Therapy, 8, 179-184. https://doi.org/10.4172/1948-5956.1000411

[28] Loh, S.Y., Packer, T., Chinna, K. and Quek, K.F. (2013) Effectiveness of a Patient Self-Management Program for Breast Cancer as a Chronic Illness: A Non-Randomised Controlled Clinical Trial. Journal of Cancer Survivorship: Research and Practice, 7, 331-342.

[29] White, K.M. (2016) The Role of the Occupational Therapist in the Care of People Living with Lung Cancer. Translational Lung Cancer Research, 5, 244-246. https://doi.org/10.21037/tlcr.2016.05.02

[30] Fallahpour, M., Tham, K., Joghataei, M.T., Eriksson, G. and Jonsson, H. (2011) Occupational Gaps in Everyday Life after Stroke and the Relation to Functioning and Perceived Life Satisfaction. OTJR: Occupation, Participation and Health, 31, 200-208. https://doi.org/10.3928/15394492-20110513-01

[31] Bergström, A., Erickson, G., Guidetti, S. and Tham, K. (2016) Satisfaction Is Associated with Participation: Everyday Occupations Measured with the Occupational Gaps Questionnaire. The American Journal of Occupational Therapy, 70, Article ID: 7011505166. https://doi.org/10.5014/ajot.2016.70S1-PO6050

[32] Law, M., Cooper, B.A., Strong, S., Stewart, D., Rigby, P. and Letts, L. (1996) The Person-Environment-Occupation Model: A Transactive Approach to Occupational 
Performance. Canadian Journal of Occupational Therapy, 63, 9-23. https://doi.org/10.1177/000841749606300103

[33] Strong, S., Rigby, P., Stewart, D., Law, M., Letts, L. and Cooper, B. (1999) Application of the Person-Environment-Occupation Model: A Practical Tool. Canadian Journal of Occupational Therapy, 66, 122-133.

https://doi.org/10.1177/000841749906600304

[34] World Federation of Occupational Therapists, Mackenzie, L., Coppola, S., Alvarez, L., et al. (2017) International Occupational Therapy Research Priorities: A Delphi Study. OTJR: Occupation, Participation and Health, 37, 72-81.

https://doi.org/10.1177/1539449216687528

[35] Methley, A.M., Campbell, S., Chew-Graham, C., McNally, R. and Cheraghi-Sohi, S. (2014) PICO, PICOS and SPIDER: A Comparison Study of Specificity and Sensitivity in Three Search Tools for Qualitative Systematic Reviews. BMC Health Services Research, 14, Article No. 579. https://doi.org/10.1186/s12913-014-0579-0

[36] Wildridge, V. and Bell, L. (2002) How CLIP Became ECLIPSE: A Mnemonic to Assist in Searching for Health Policy/Management Information. Health Information and Libraries Journal, 19, 113-115. https://doi.org/10.1046/j.1471-1842.2002.00378.x

[37] Cooke, A., Smith, D. and Booth, A. (2012) Beyond PICO: The SPIDER Tool for Qualitative Evidence Synthesis. Qualitative Health Research, 22, 1435-1443. https://doi.org/10.1177/1049732312452938

[38] Pollock, A. and Berge, E. (2018) How to Do a Systematic Review. International Journal of Stroke, 13, 138-156. https://doi.org/10.1177/1747493017743796

[39] World Health Organization (2008) WHO Commission on Social Determinants of Health, Closing the Gap in a Generation: Health Equity through Action on the Determinants of Health-Final Report. Geneva, Switzerland. http://www.who.int/social determinants/thecommission/finalreport/en/

[40] American Occupational Therapy Association (2015) Occupational Therapy's Perspective on the Use of Environments and Contexts to Facilitate Health, Well-Being, and Participation in Occupations. American Journal of Occupational Therapy, 69, Article ID: 6913410050. https://doi.org/10.5014/ajot.2015.696S05 